\title{
STOCHASTIC CHARACTERISTIC OF SITE AMPLIFICATION FACTOR AND ITS EFFECT ON EARTHQUAKE GROUND MOTION
}

\author{
YASUHIRO FUKUSHIMA ${ }^{1} \&$ TAKASHI NAGAO ${ }^{2}$ \\ ${ }^{1}$ Eight-Japan Engineering Consultants Inc. (EJEC), Japan \\ ${ }^{2}$ Research Center for Urban Security and Safety, Kobe University, Japan
}

\begin{abstract}
Evaluation of the variations of the design earthquake ground motion is very important, because the safety margins shall be set according to the variations of design variables in the earthquake resistant design. Earthquake ground notion is expressed by the multiplication of source characteristic, path characteristic and site amplification characteristic in the frequency domain. Although the source and path characteristics can be evaluated analytically, site amplification characteristic can only be evaluated precisely in an empirical manner by using the strong motion record because site amplification characteristic is strongly affected by the sedimentary environment of soil layers at the site of interest. Little study on the stochastic characteristic of site amplification factor has been done so far. In this paper, the authors evaluated the stochastic characteristic of site amplification factor by the spectral analysis on the strong motion records observed at two sites: reference site and target site. Variation of the representative value of earthquake ground motion such as peak ground acceleration and peak ground velocity considering the variation of site amplification factor is discussed.
\end{abstract}

Keywords: earthquake ground motion, site amplification factor, stochastic characteristic.

\section{INTRODUCTION}

It is necessary to evaluate the design earthquake ground motion adequately for the earthquake resistant design of infrastructures. Earthquake ground motion can be evaluated by considering source characteristic, path characteristic and site amplification characteristic (Nozu et al. [1]). Here, site amplification characteristic implies the amplification factor in the frequency domain caused by the deep subsurface ground condition, namely the ground condition from the ground surface to the seismic bedrock at the site of interest. It is known that the site amplification greatly differs from site to site. As the site amplification factor is strongly affected by both the 3-dimensional sedimentary environment of soil layers at the site of interest and incident angle of seismic wave, it can only be evaluated precisely in an empirical manner by using the strong motion record. Spectral inversion technique (Aki [2]) that separate source and path characteristics from the observed record is used for the purpose and site amplification factors at many strong-motion observation sites are published (Nozu et al. [1]).

Technical standards for infrastructures stipulate the allowable safety margins for the earthquake resistant design. As the safety margins shall be set according to the variations of design variables, evaluation of the variations of the variables is very important.

Although many studies (Morikawa et al. [3]) have been conducted on the variations of the representative values of earthquake ground motion (e.g. peak ground acceleration and peak ground velocity) by using attenuation relation (Kanno et al. [4]), little studies (Satoh et al. [5]) have been conducted on the variations of the site amplification factor. In this study, authors evaluated the variations of the site amplification factors by using strong motion records observed at plural sites. The effect of the variations of the site amplification factors on the representative values of strong motion such as peak ground velocity was discussed. 
The relation between the average representative values and the design representative values were shown.

\section{EVALUATION METHOD OF SITE AMPLIFICATION FACTORS}

$R$ denotes the reference site where its site amplification factor is known and $T$ denotes the target site where site amplification factor is to be obtained. The Fourier amplitude spectra of the observation records of earthquake ground motion at both sites $O_{R}(f)$ and $O_{T}(f)$ can be expressed by eqns (1) and (2) as the multiplication of source effect $S(f)$, path effects $P_{R}(f)$ and $P_{T}(f)$, and site effects $G_{R}(f)$ and $G_{T}(f)$ (Su et al. [6]).

$$
\begin{aligned}
& O_{R}(f)=S(f) \cdot P_{R}(f) \cdot G_{R}(f), \\
& O_{T}(f)=S(f) \cdot P_{T}(f) \cdot G_{T}(f),
\end{aligned}
$$

where path effects $P_{R}(f)$ and $P_{T}(f)$ are expressed with eqns (3) and (4). Here, $f$ is the frequency.

$$
\begin{aligned}
& P_{R}(f)=\exp \left\{-\left(\pi f r_{R}\right) /\left(Q(f) V_{S}\right)\right\} / r_{R}, \\
& P_{T}(f)=\exp \left\{-\left(\pi f r_{T}\right) /\left(Q(f) V_{S}\right)\right\} / r_{T},
\end{aligned}
$$

where, $r_{R}$ and $r_{T}$ are the hypocentral distances to site $R$ and $T$ respectively, and $Q(f)$ is the $Q$ value along the propagation path, and $V_{s}$ is the shear wave velocity. Here, $Q$ value is one of the parameters expressing the attenuation characteristic of seismic waves with distance (Petukhin et al. [7]). In the past research, the $Q$ value is expressed as a function of frequency and it is known that the $Q$ value differs from region to region. For example, Satoh et al. [8] showed the $Q$ value of the eastern Tohoku district, Japan as:

$$
Q(f)=110 f^{0.69} \text {. }
$$

In this study, we use eqn (6) for the $Q$ value of the subduction earthquake in eastern Japan estimated by Satoh and Tatsumi [9].

$$
Q(f)=114 f^{0.92} \text {. }
$$

From the above, the site amplification factor of site $T, G_{T}(f)$ is expressed with eqn (7).

$$
G_{T}(f)=G_{R}(f) \cdot \frac{O_{T}(f)}{O_{R}(f)} \cdot \frac{r_{T}}{r_{R}} \cdot \frac{\exp \left\{-\left(\pi f r_{R}\right) /(Q(f) V s)\right\}}{\exp \left\{-\left(\pi f r_{T}\right) /(Q(f) V s)\right\}} .
$$

\section{VARIATION OF SITE AMPLIFICATION FACTORS}

Three K-NET [10] earthquake ground motion observation stations in Fukushima and Ibaraki prefectures in Japan, indicated in Fig. 1 was chosen for the study. Fig. 2 indicates the site amplification factor by the spectral inversion [1] for the 3 target sites. For each observation station, the number of earthquake records used for spectral inversion is indicated in Table 1. FKS013 and IBR002 have predominant peaks at frequencies lower than $2 \mathrm{~Hz}$, and these sites have relatively thick sedimentary layers. On the contrary, IBR003 has predominant peaks at frequencies higher than $3 \mathrm{~Hz}$ site and the site has relatively thin sedimentary layers.

Among the 3 sites, IBR003 was set to be the target site. Variation of the site amplification factors was calculated with eqn (7). Note that the observation records with good signal to noise ratio were chosen from the viewpoint of compatibility with the $\omega^{-2}$ theory (Aki [11]). Here, $\omega$ is the angular frequency $(=2 \pi f)$. 


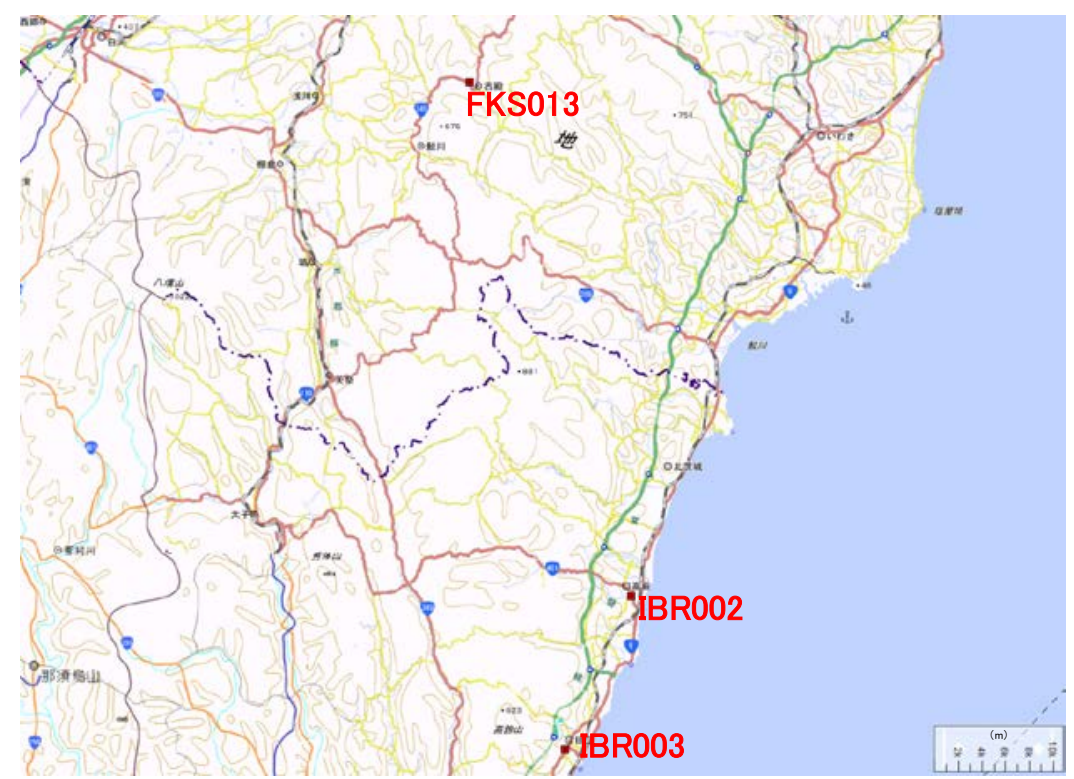

Figure 1: Earthquake ground motion observation stations [9] used for this study.

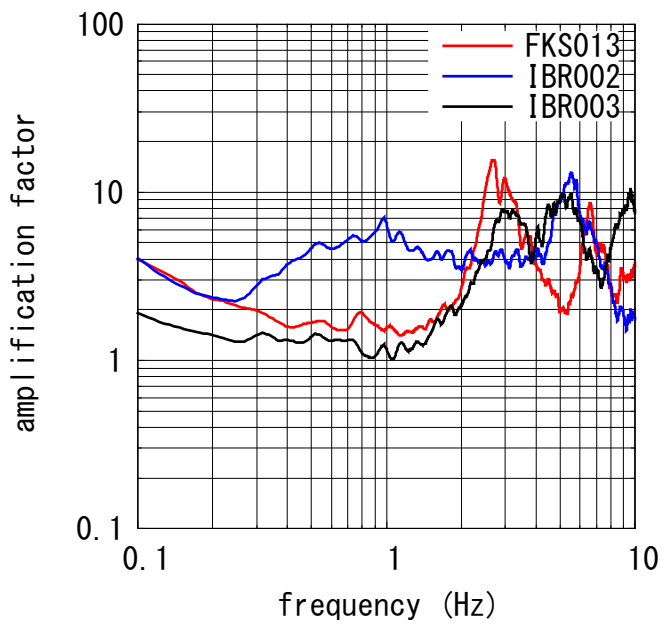

Figure 2: Site amplification factors at the 3 sites by spectral inversion [1].

Table 1: The number of earthquake records used in spectral inversion [1].

\begin{tabular}{|c|c|}
\hline Observation station & Number of earthquake records \\
\hline FKS013 & 66 \\
\hline IBR002 & 83 \\
\hline IBR003 & 74 \\
\hline
\end{tabular}


Calculated site amplification factors for IBR003 observation station are shown in Fig. 3. The number of observation records used in this study were 173 for FKS013 and 266 for IBR002. The gray solid lines show each calculated site amplification factor, the blue solid line shows average site amplification factor, the blue dotted lines show average \pm standard deviation and the red solid line shows the site amplification factor obtained by spectral inversion [1]. The average site amplification factor is roughly similar to the site amplification factor by spectral inversion [1], but there exists a difference depending on a reference site and a frequency band.

Fig. 4 shows the frequency characteristic of the standard deviations of the site amplification factor. The standard deviation becomes larger at most of the frequencies in the case where the reference site is FKS013 locating far from the target site as compared with the case where the reference site is IBR002 locating comparatively near the target site. Average standard deviation of the calculated site amplification factor in the range of 0.5 to $10.0 \mathrm{~Hz}$ was between 0.186 and 0.246 . Note that standard deviation used in this study is the logarithmic standard deviation and the frequency range was decided considering the effect on the earthquake resistance of social infrastructures. The standard deviations obtained in this study was found to be consistent with the past study. For example, Hirai and Nagao [12] reported that the standard deviation was 0.25 for observation stations in Miyagi prefecture in Japan. Fig. 5 shows examples of the distribution of the site amplification factors at frequencies 1.0 and $3.0 \mathrm{~Hz}$. Here, the site amplification factors are normalized by the average values. It can be pointed out that the distribution of the standard deviations of the site amplification factors may be regarded as the lognormal distributions.

Fig. 6 shows the relation between the distance from reference site to target site and the average standard deviations of the site amplification factors. Standard deviations of site amplification factors tend to increase as the distance between reference site and target site increases. This may be caused by the variance of the path characteristic in eqn (7).

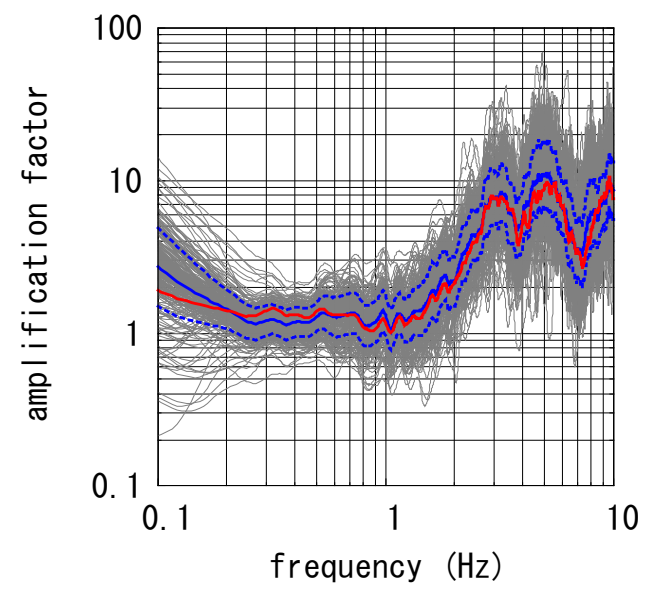

(a) R: IBR002
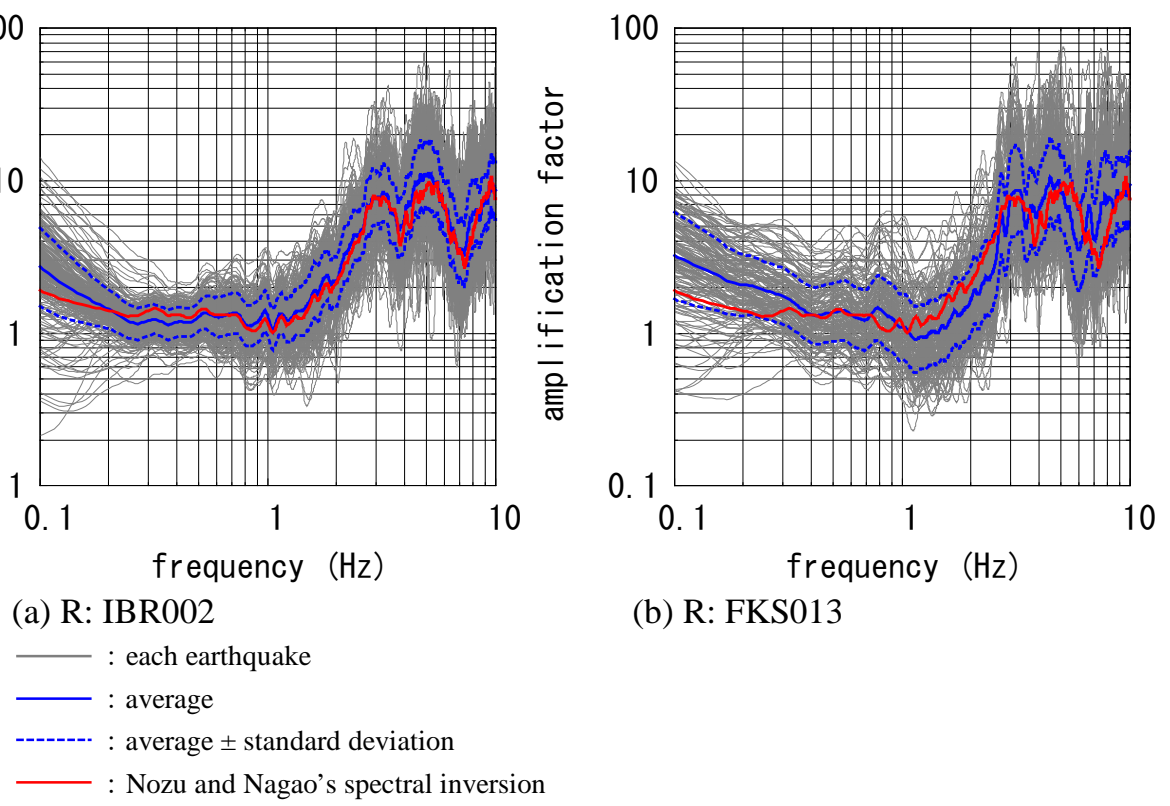

(b) R: FKS013

Figure 3: The calculated site amplification factor of IBR003. 


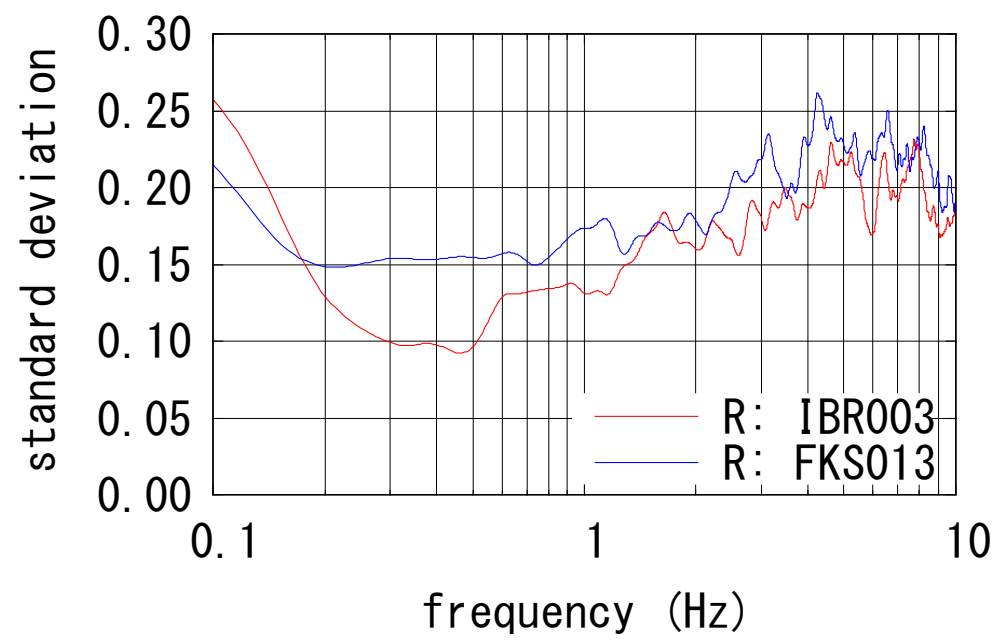

Figure 4: Frequency characteristic of the standard deviations of the site amplification factors.

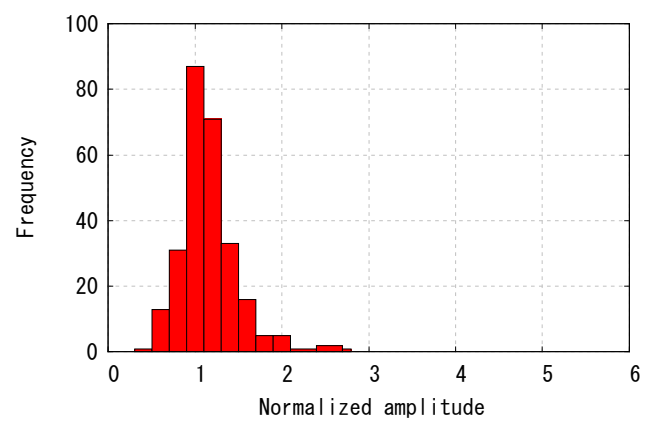

(a) $1.0 \mathrm{~Hz}$

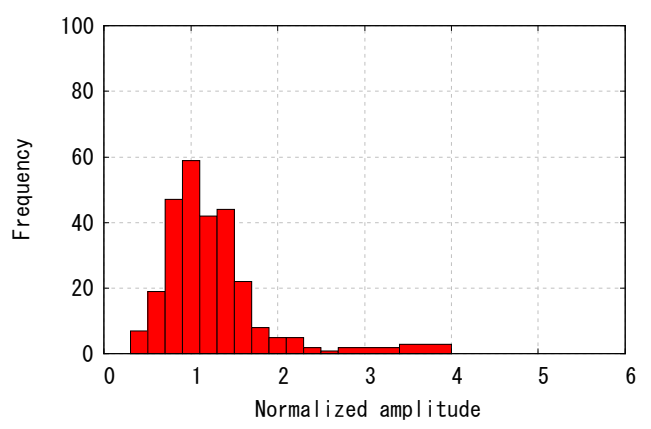

(b) $3.0 \mathrm{~Hz}$

(1) R: IBR002

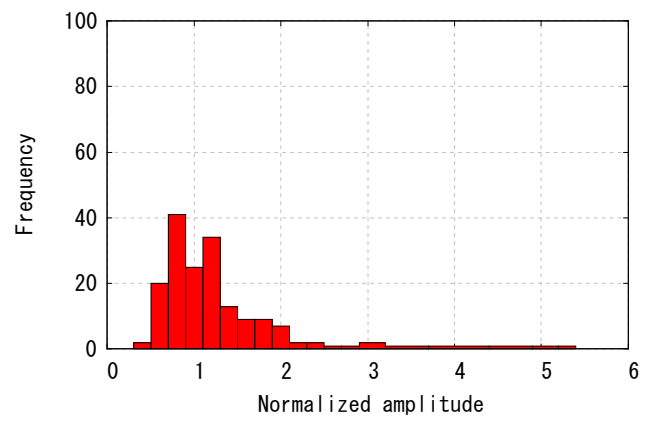

(a) $1.0 \mathrm{~Hz}$

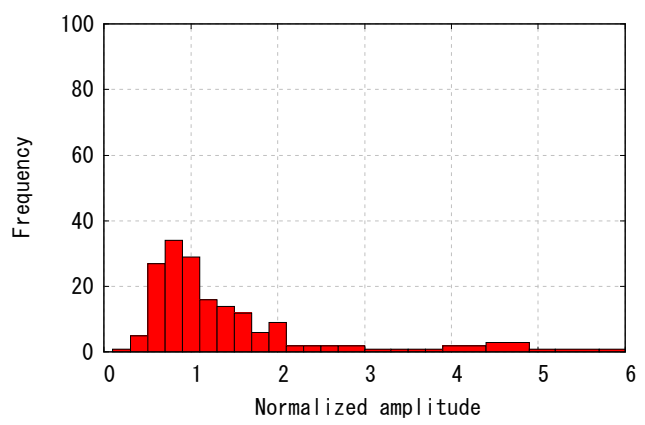

(b) $3.0 \mathrm{~Hz}$

(2) R: FKS013

Figure 5: Examples of the distribution of the standard deviations of the site amplification factors. 


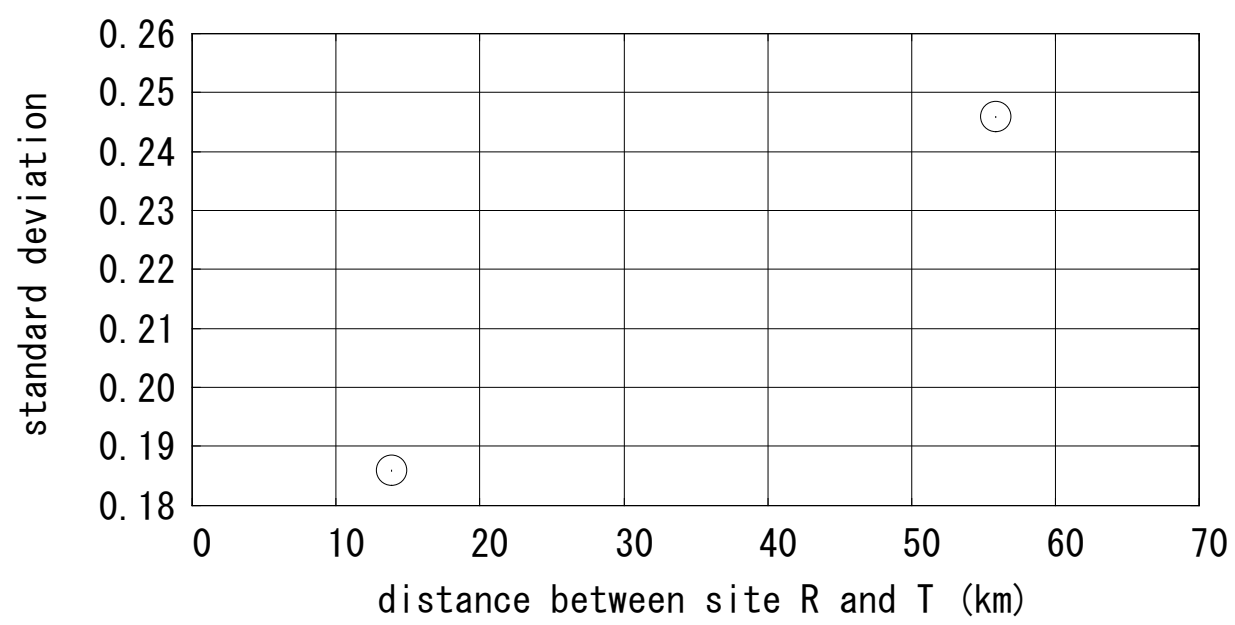

Figure 6: Relation between the distance from reference site to target site and the standard deviation of site amplification factors.

\section{VARIATION OF EARTHQUAKE GROUND MOTION CONSIDERING VARIATION OF SITE AMPLIFICATION FACTORS}

In Japan, two-stage design earthquake ground motions for the earthquake-resistant design of public works were introduced after the 1995 Kobe earthquake. One of the two-stage design earthquake ground motions is called as the Level-one earthquake ground motions which presumably occur with certain degree of frequency during the design working period of infrastructure. The earthquake ground motion corresponds to the reference earthquake ground motions for evaluating serviceability of structures specified in ISO23469 [13].

In this study, the Level-one earthquake ground motions at IBR003 observation station were calculated considering the variations of the site amplification factors discussed so far. Probabilistic seismic hazard analysis with focus on Fourier amplitude and group delay time proposed by Nagao et al. [14] was used for the calculation of the earthquake ground motions. Fig. 7 shows the time history of calculated Level-one earthquake ground motions with average site amplification factor and that obtained by the spectral inversion. Peak ground accelerations are $355.1,422.8$ and $316.6 \mathrm{~cm} / \mathrm{s}^{2}$ for site amplification factors with the average by IBR002, FKS013 and that by the spectral inversion respectively. There exists a difference in the peak ground accelerations that cannot be ignored. Fig. 8 shows the Fourier amplitude spectra of the earthquake ground motions. Here, Fourier amplitude spectra were smoothed with Parzen window of band width $0.05 \mathrm{~Hz}$. The difference in the peak ground accelerations is caused by the difference in the Fourier amplitude spectra and as the Fourier amplitude spectra is calculated by the multiplication of source spectra, path spectra and site amplification factor, it is obvious that the difference in the peak ground accelerations is caused by the difference in the site amplification factor.

Fig. 9 shows the frequency distributions of peak ground accelerations and peak ground velocities. Although peak ground acceleration is often used for the earthquake resistant design of infrastructures, it is well known that there is a strong correlation between peak ground velocity and the damage level of structures. Both distributions of the peak ground accelerations and the peak ground velocities may be regarded as the lognormal distributions. 
Both the peak ground accelerations and peak ground velocities of the earthquake ground motions considering the average site amplification factor are smaller than the average values of those of the earthquake ground motions. The average ratios of the former to the latter were 0.90 for the peak ground acceleration and 0.87 for the peak ground velocity. From the above, it is suggested that utmost care is required for setting the design earthquake ground motion because the evaluation of the earthquake ground motion with the average site amplification factor may lead to the earthquake resistant design on the dangerous side.

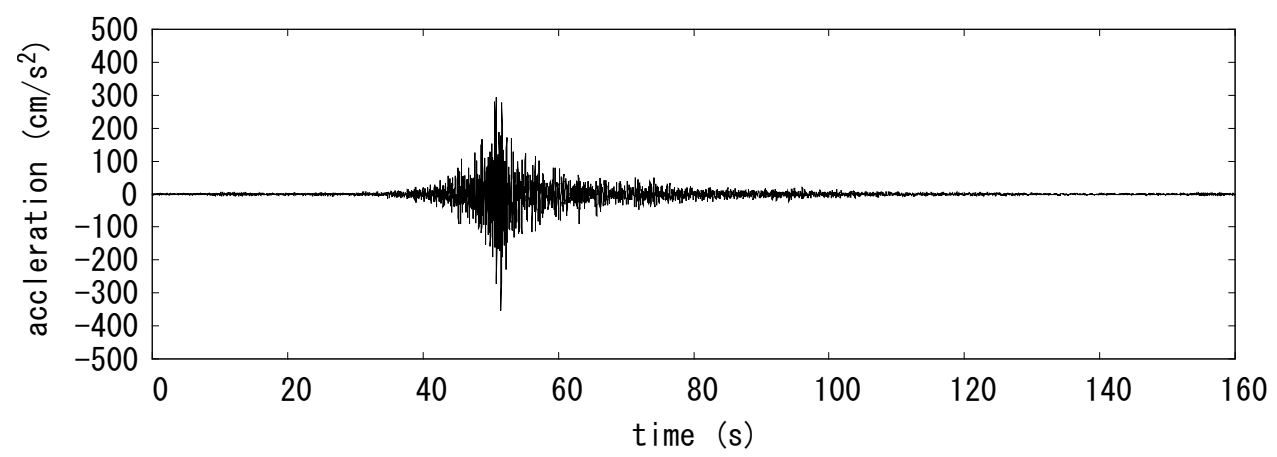

(a) With the average site amplification factors by IBR002.

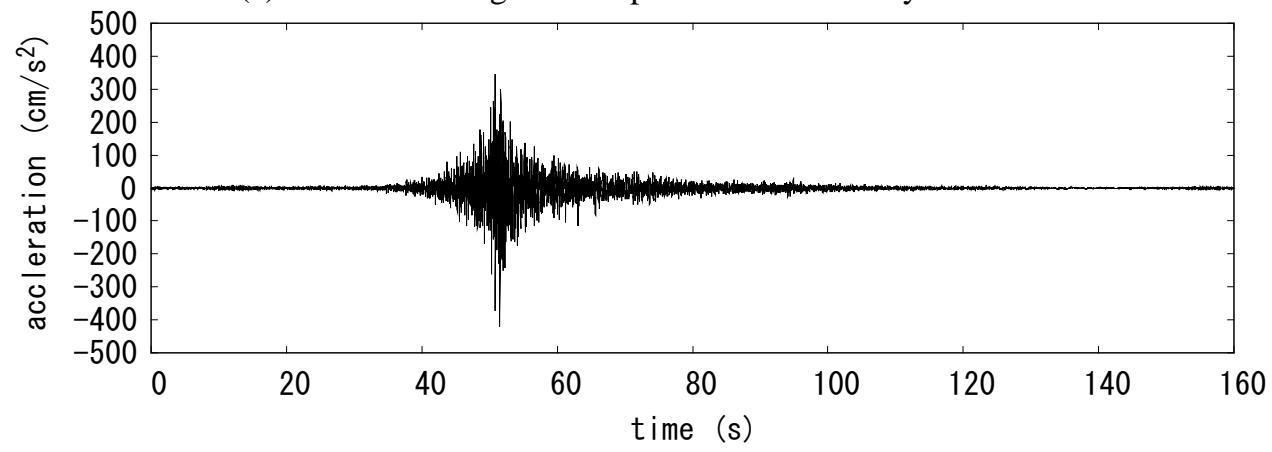

(b) With the average site amplification factors by FKS013.

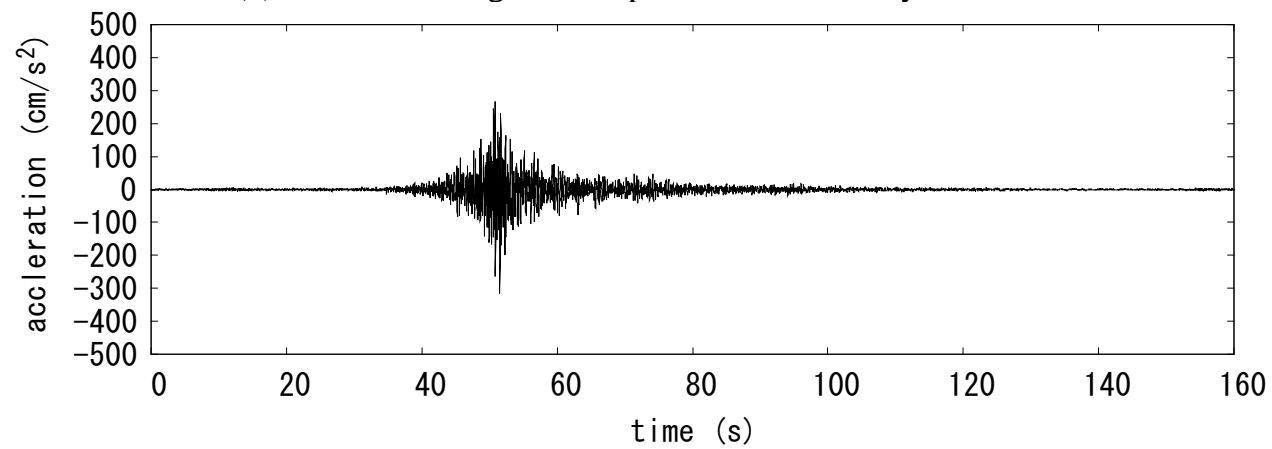

(c) With the average site amplification factors by the spectral inversion.

Figure 7: Examples of the time history of the Level-one earthquake ground motions. 


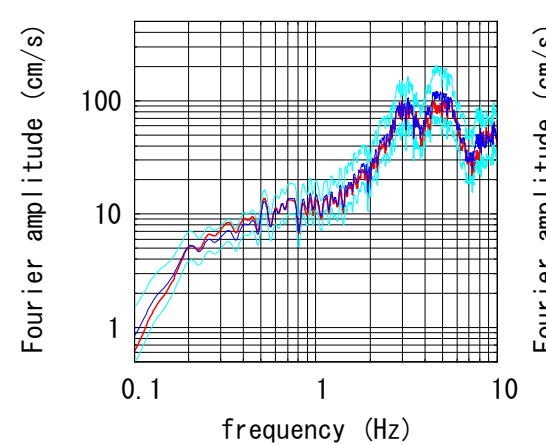

(a) R: IBR002

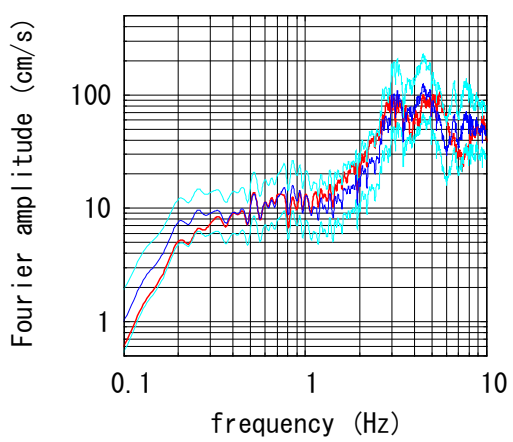

(b) R: FKS013

— : considering the average site amplification factor

— : considering the average \pm standard deviation site amplification factor

: considering site amplification factor by Nozu and Nagao's spectral inversion

Figure 8: Fourier amplitude spectra of the Level-one earthquake ground motions.

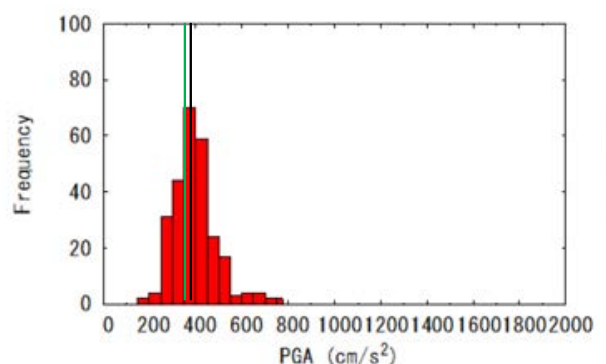

(a) R: IBR002

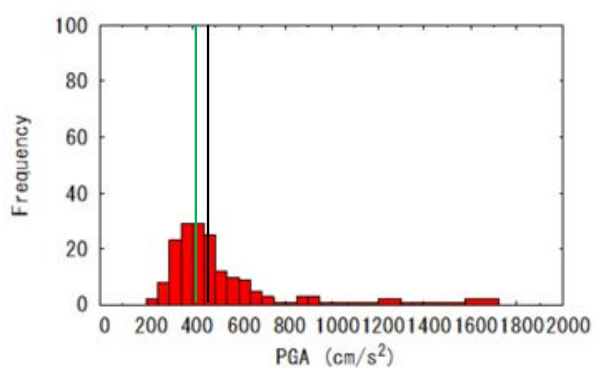

(b) R: FKS013

(1) Peak ground acceleration

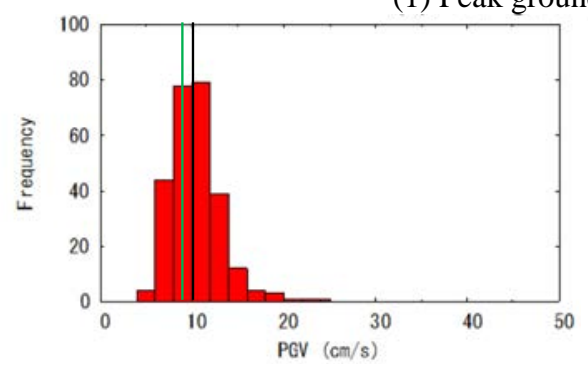

(a) R: IBR002

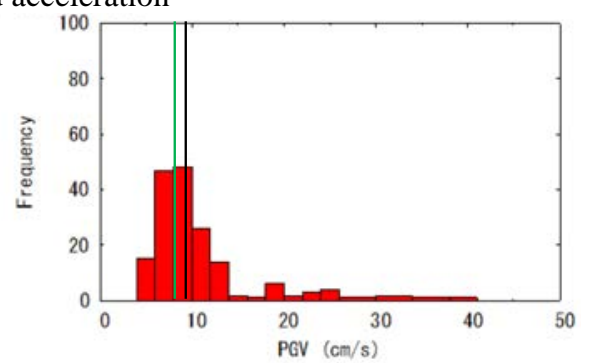

(b) R: FKS013

(2) Peak ground velocity

— : considering the average site amplification factor

— : average value

Figure 9: Frequency distributions of peak ground accelerations and peak ground velocities.

Fig. 10 shows the relation between the standard deviations of the peak ground acceleration and the peak ground velocity and those of the site amplification factors. The average ratios of the former to the latter were 0.60 for the peak ground acceleration and 0.67 for the peak ground velocity. 


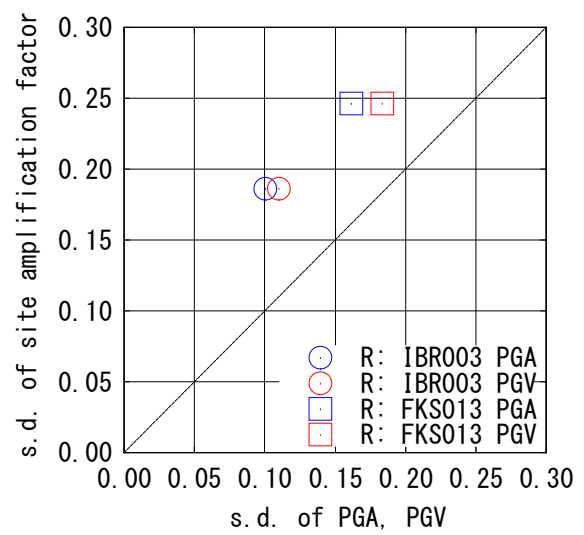

Figure 10: The relation between the standard deviations of the peak ground acceleration and the peak ground velocity and those of the site amplification factors.

\section{CONCLUSION}

In this study, by using simultaneous observation record at neighbouring earthquake ground motion observation stations, the variations of the site amplification factors was evaluated with IBR003 earthquake ground motion observation stations in Ibaraki prefecture in Japan. Furthermore, the earthquake ground motion considering the variation of the site amplification factors was calculated, and the relation between the variation of the site amplification factors and the variation of representative values of earthquake ground motion was discussed. The following findings were derived from the study.

1. The larger the distance between the reference site and the target site, the larger the site amplification factor variation tends to be.

2. Both the peak ground accelerations and the peak ground velocities of the earthquake ground motions considering the average site amplification factor are smaller than the average values of those of the earthquake ground motions.

3. Utmost care is required for setting the design earthquake ground motion because the evaluation of the earthquake ground motion with the average site amplification factor may lead to the earthquake resistant design on the dangerous side.

Note that these findings were derived from the strong motion records observed at three earthquake ground motion observation stations in Ibaraki prefecture in Japan. Further work on the applicability of these findings to the other strong motion records is on the way to discuss the reasonable seismic motion setting method.

\section{ACKNOWLEDGEMENT}

We would like to thank the National Research Institute for Earth Science and Disaster Prevention, Japan, for providing us with K-NET strong motion records.

\section{REFERENCES}

[1] Nozu, A., Nagao, T. \& Yamada, M., A strong motion simulation method suitable for areas with less information on subsurface structure. Proceedings of the 14th World Conference on Earthquake Engineering, 2008. 
[2] Aki, K., Analysis of seismic coda of local earthquakes as scattered waves. J. Geophys. Res., 74, pp. 615-631, 1969.

[3] Morikawa, N., Kanno, T., Narita, A., Fujiwara, H., Okumura, T., Fukushima, Y. \& Guerpinar, A., Strong motion uncertainty determined from observed records by dense network in Japan. J. Seism., 12, pp. 529-546, 2008.

[4] Kanno, T., Narita, A., Morikawa, N., Fujiwara, H. \& Fukushima, Y., A new attenuation relation for strong ground motion in Japan based on recorded data. Bull. Seism. Soc. Am., 96(3), pp. 879-897, 2006.

[5] Satoh, T., Kawase, H. \& Sato, T., Evaluation of local site effects and their removal from borehole records observed in the Sendai region, Japan. Bull. Seism. Soc. Am., 85(6), pp. 1770-1789, 1995.

[6] Su, F., Aki, K., Teng, T., Zeng, Y., Koyanagi, S. \& Mayeda, K., The relation between site amplification factor and surficial geology in central California. Bull. Seism. Soc. Am., 82(2), pp. 580-602, 1992.

[7] Petukhin, A., Irikura, K., Ohmi, S. \& Kagawa, T., Estimation of Q-values in the seismogenic and aseismic layers in the Kinki region, Japan, by elimination of the geometrical spreading effect using ray approximation. Bull. Seism. Soc. Am., 93(4), pp. 1498-1515, 2003.

[8] Satoh, T., Kawase, H. \& Sato, T., Statistical spectral model of earthquakes in the Eastern Tohoku District, Japan, based on the surface and borehole records observed in Sendai. Bull. Seism. Soc. Am., 87(2), pp. 446-462, 1997.

[9] Satoh, T. \& Tatsumi, Y., Source, path, and site effects for crustal and subduction earthquakes inferred from strong motion records in Japan. J. Struct. Constr. Eng. AIJ, 556, pp.15-24, 2002. (In Japanese.)

[10] Kinoshita, S., Kyoshin Net (K-NET). Seism. Res. Lett., 69, pp. 309-332, 1998.

[11] Aki, K., Scaling law of seismic spectrum. J. Geophys. Res., 72, pp. 1217-1231, 1967.

[12] Hirai, T. \& Nagao, T., A simple estimation method of the probability distribution of residual deformation of gravity type quay walls considering the variation of earthquake ground motion. IALCCE2016, pp. 485-491, 2016.

[13] Iai, S., Seismic actions for designing geotechnical works - ISO23469. Journal of Japan Association for Earthquake Engineering, 4(3) (Special Issue), 2004.

[14] Nagao, T., Yamada, M. \& Nozu, A., Probabilistic seismic hazard analysis with focus on Fourier amplitude and group delay time. Proceedings of the 15th World Conference on Earthquake Engineering, 2012. 